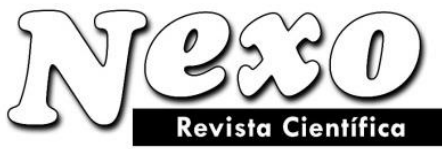

Vol. 34, No. 01, pp. 825-834/Junio 2021

\title{
Stress filed data visualization by using earthquake focal mechanism and shear wave splitting results in the Makran region northern Iran
}

\author{
Visualización de datos de campo de estrés utilizando mecanismo focal de \\ terremoto y resultados de división de ondas de corte en la región de Makran \\ en el norte de Irán
}

\author{
Shahrokh Pourbeyranvand \\ Seismology dept., International Institute of Earthquake Engineering and Seismology, Tehran, \\ Iran. \\ *beyranvand@iiees.ac.ir
}

(recibido/received: 12-enero-2021; aceptado/accepted: 17-abril-2021)

\begin{abstract}
In this study, a new method is introduced for stress data visualization. As an example, the SHmax variations in the Makran region are mapped by using this new approach. Maximum horizontal stress directions in the study area are extracted from earthquake focal mechanism data. The anisotropy study results in terms of shear wave splitting fast direction axes are added to the dataset to show its effect. The results show substantial variation in SHmax directions, which reflects the complicated tectonic nature of the region. Adding the shear wave splitting data improved the results' accuracy and showed the correlation between the two quantities in the study area.
\end{abstract}

Keywords: Direction, Stress, Tectonic, Visualization, Zagros Makran transition zone

\section{RESUMEN}

En este estudio, se introduce un nuevo método para la visualización de datos de estrés. Como ejemplo, las variaciones de SHmax en la región de Makran se mapean utilizando este nuevo enfoque. Las direcciones de tensión horizontal máxima en el área de estudio se extraen de los datos del mecanismo focal del terremoto. Los resultados del estudio de anisotropía en términos de ondas de corte que dividen los ejes de dirección rápida se agregan al conjunto de datos para mostrar su efecto. Los resultados muestran una variación sustancial en las direcciones SHmax, lo que refleja la complicada naturaleza tectónica de la región. La adición de los datos de división de la onda de corte mejoró la precisión de los resultados y mostró la correlación entre las dos cantidades en el área de estudio.

Palabras claves: Dirección, Tensión, Tectónica, Visualización, Zona de transición de Zagros Makran. 


\section{INTRODUCTION}

Many achievements have been accomplished about color theory from early works by the great scientist Sir Isaac Newton who the color circle is stemmed from his ideas until recent progress in this domain by the aid of modern computer systems (Shevell, 2003). However, the illustration of the direction-dependent data or vector directions is not an easy and intuitive task to do as it seems. Maybe this is why nobody has attempted to find or publish the solution to this problem so far. There is a well-known potential solution to this problem called the color wheel or color circle, but it has not been implemented yet. As we will see, this is not the correct answer to many problems, especially the example we will discuss in this paper.

For the illustration of unidirectional data, it is enough to use the color wheel, which is introduced in the relevant references before but has not been used as a basis for visualizing vector data directions so far. The so-called unidirectional data can be visualized using the color wheel, as we will see in the afterward sections of this paper. But the illustration of bidirectional vectors requires further innovation and the creation of a new color circle by a new RGB combination scheme, which will be addressed in this paper.

In the following sections, we will review the tectonic setting of the Makran zone to emphasize the importance of the stress studies in this Seismo-structurally complicated zone. Then we will go through the seismicity and earthquakes in the region and extract stress information from single focal mechanism data. Then the new method of visualization of vector data direction is proposed and the procedure is implemented. After that, the anisotropy results from shear wave splitting studies in the region are added to the obtained stress map. Finally, the results are interpreted according to the geology of the area and new findings of this research are discussed.

\section{TECTONIC SETTING OF THE STUDY AREA}

Iran has suffered many great earthquakes, with many casualties and enormous damages. Meanwhile, advances in civil, mining, and petroleum engineering have led to the development of stress measurement technologies over the past century. It is essential to learn about the stress field in geosciences to understand folded structures' development, moving on faults that cause earthquakes. During the convergence between the Arabian plate and Eurasia, the relative north-northeast movement of the Arabian plate relative to Eurasia from west to east changes from 18 to $25 \mathrm{~mm}$ per year, and the pole of this rotation is in North Africa (Masson et al., 2005; Raeesi, Zarifi, Nilfouroushan, Boroujeni, \& Tiampo, 2017; Vernant et al., 2004). Knowing about stress variations in the Zagros and Makran transition zone, southwest Iran is necessary to study the deformation resulting from the oblique collision between the Eurasian and the Arabian plates and gain insight into the complicated tectonics of this critical region (Figure 1).

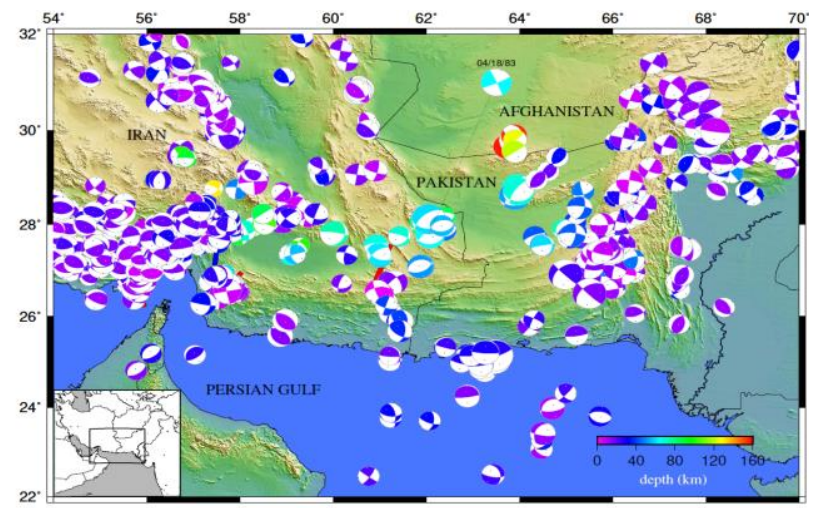

Figure 1. Map of the study area, including the focal mechanisms used in this study, taken from various references described in the text in addition to active faults overlaid on topography. The small colored circles show the seismicity from 1960 to 2020 from IRSC concerning the events' depth. 


\section{EXTRACTION OF MAXIMUM HORIZONTAL STRESS DIRECTIONS FROM DINGLE FOCAL MECHANISM DATA}

In addition to usual faulting regimes including normal (NF), thrust or reverse (TF), and strike-slip faulting (SS), combinations of normal with strike-slip faulting or transtension (NS) and thrust with strike-slip faulting or transpression (TS) are also introduced (Zoback, 1992). These stress regimes are shown in Fig. 2. The plunges of $P, B$ and $T$ axes are used to determine the $\sigma 1$ or maximum stress direction concerning the specific stress regime, as shown in Table 1 (Zoback, 1992).
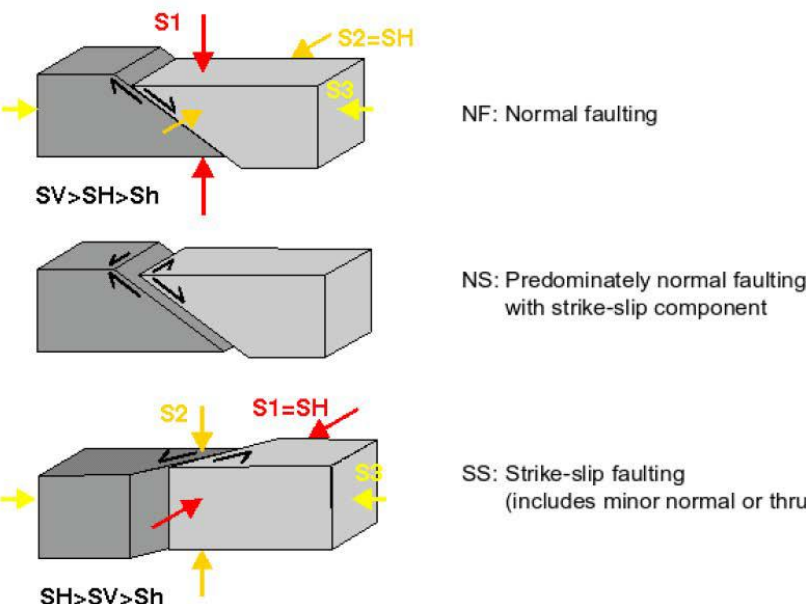

SS: Strike-slip faulting

(includes minor normal or thrust component)

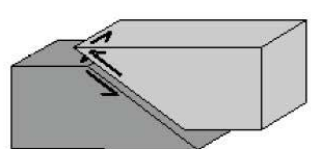

TS: Predominately thrust faulting with strike-slip component

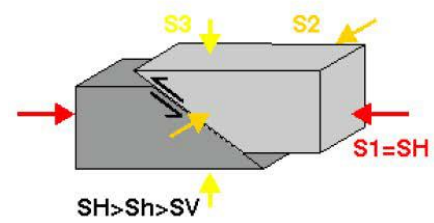

TF: Thrust faulting

Figure 2. Classification of the five different tectonic stress regimes and the related orientations of the principal stress axes (Heidbach, Rajabi, Reiter, \& Ziegler, 2016).

Table 1. Determination of $\sigma 1$ directions from P, T B axes orientations based on different tectonic Stress Regimes

\begin{tabular}{ccccl}
\hline $\mathbf{P} / \mathbf{S 1 - a x i s}$ & $\mathbf{B} / \mathbf{S 2}$-axis & T/S3-axis & Regime & \multicolumn{1}{c}{$\mathbf{S}_{\mathrm{H}^{-}}$azimuth } \\
\hline $\mathrm{pl}>52$ & & $\mathrm{pl}<35$ & $\mathrm{NF}$ & azim. of B-axis \\
$40<\mathrm{pl}<52$ & & $\mathrm{pl}<20$ & $\mathrm{NS}$ & azim. of T-axis $+90^{\circ}$ \\
$\mathrm{pl}<40$ & $\mathrm{pl}>45$ & $\mathrm{pl}<20$ & $\mathrm{SS}$ & azim. of T-axis $+90^{\circ}$ \\
$\mathrm{pl}<20$ & $\mathrm{pl}>45$ & $\mathrm{pl}<40$ & $\mathrm{SS}$ & azim. of $\mathrm{P}$-axis \\
$\mathrm{pl}<20$ & & $40<\mathrm{pl}<52$ & $\mathrm{TS}$ & azim. of P-axis \\
$\mathrm{pl}<35$ & & $\mathrm{pl}>52$ & $\mathrm{TF}$ & azim. of P-axis \\
\hline
\end{tabular}




\section{EARTHQUAKE FOCAL MECHANISM DATA}

The earthquake focal mechanism data for the study area, obtained through several different sources, are plotted in Figure 3. It can be seen that most of the events, as expected, are reverse or strike-slip, which indicate the transpressional tectonic environment prevailing in the region. Some normal mechanisms can also be observed in the area caused by local extensional regimes due to the interaction between blocks or folds.

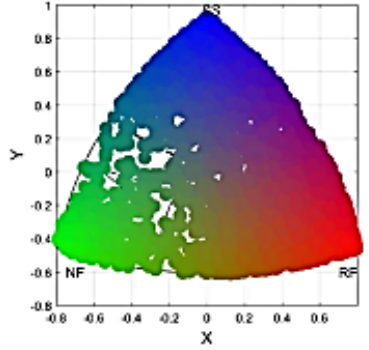

All

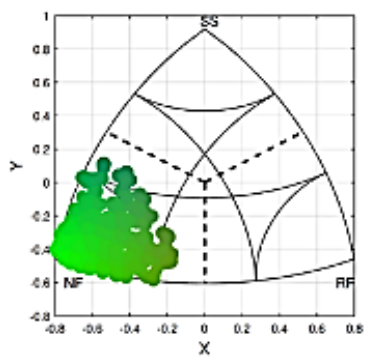

NF

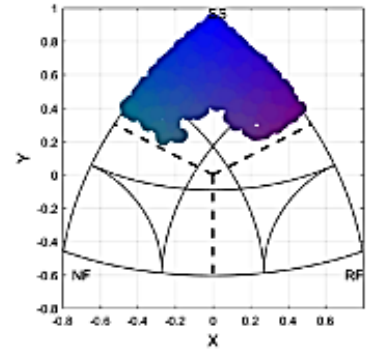

SS

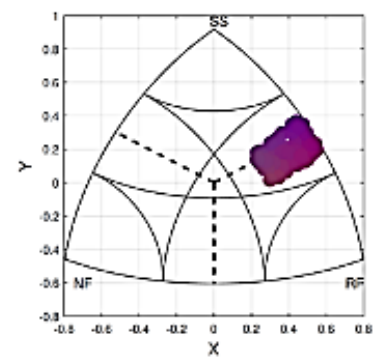

TS

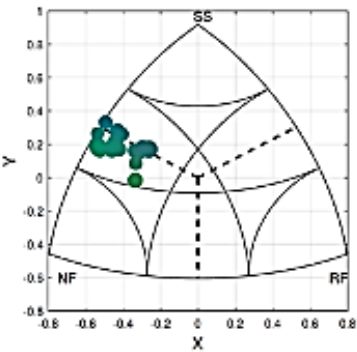

NS

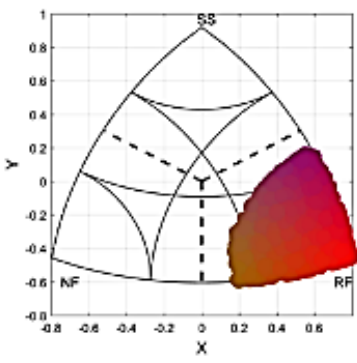

TF

Figure 3. Kagan's triangular diagram showing the nature of faulting mechanisms all over the study area. The color of the circles indicates the mechanism of the faulting, which is red for pure reverse, green for pyre normal and blue for pure strike-slip events.

The sources from which the earthquake focal mechanisms are collected, including the GCMT website (formerly abbreviated HRVD), the website of the Seismological Center of the Institute of Geophysics, University of Tehran (IRSC), the International Seismological Center (ISC) website, the US National Earthquake Information Center website (NEIC) and the website of the Swiss Seismological Service ZUR_RMT. Numerous articles were also used to complete the data set. The time frame of the focal mechanism data used in this study is from 1970 to 2020. Thus, the sources used to build the database of this study consist of teleseismic data (international research centers including GCMT, USGS and ISC) and local data (including the focal mechanism data of the Seismological Center of the Institute of Geophysics, University of Tehran (IRSC) and the results published from local networks in the form of scientific articles). Regarding the errors in the data and their impact on the results, it should be mentioned that the uncertainty in the parameters of the focal mechanism of earthquakes is about 15 to 20 degrees.

\section{INTRODUCING A NEW METHOD IN VISUALIZING THE DIRECTION OF VECTOR DATA}

The first solution to solve this problem, i.e., showing the direction by a color scale, is to assign RGB combinations in different directions. But if you increase one, two, or three RGB values, the result is not satisfying because the color contrast between 0 and 359, which should be very little according to the definition as mentioned earlier of the bidirectional vectors, will be the highest value, which is apparently false. On the other hand, the color of each direction and its neighbor, which is the same angle +180 
degrees, should be the same. This makes the problem a little bit more challenging and totally differentiates the problem and solution with the case of unidirectional vectors and the color wheel. To clarify the situation, we need to go through the detail of the RGB combinations of the color wheel and the proposed new circle with central symmetry in colors, which we will call color half circle afterward. We will deal with these in the future. The RGB combination of the color circle, which is introduced in relevant references, is so that every direction (or direction interval more precisely) is represented by a unique color. But in the proposed new color wheel, this problem is solved (Figure 4):

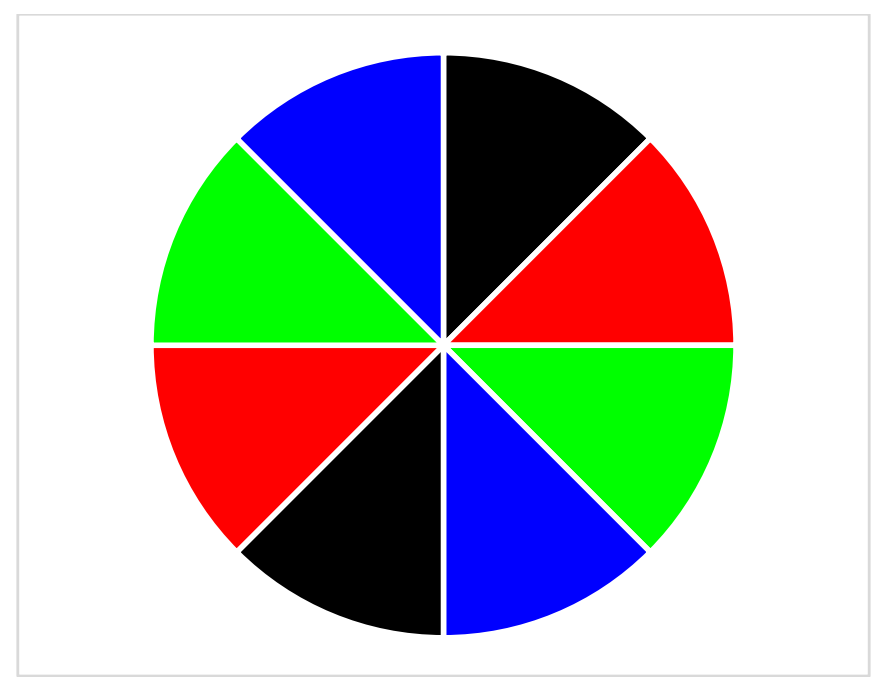

Figure 4. The proposed color wheel or the proposed color circle

The RGB values for this new circle are shown in Table 2:

Table 2. RGB values for the proposed color circle

\begin{tabular}{|c|c|c|c|}
\hline & $\mathbf{R}$ & $\mathbf{G}$ & $\mathbf{B}$ \\
\hline $\mathbf{0}$ & 0 & 0 & 0 \\
\hline $\mathbf{4 5}$ & 256 & 0 & 0 \\
\hline $\mathbf{9 0}$ & 0 & 256 & 0 \\
\hline $\mathbf{1 3 5}$ & 0 & 0 & 256 \\
\hline $\mathbf{1 8 0}$ & 0 & 0 & 0 \\
\hline $\mathbf{2 2 5}$ & 256 & 0 & 0 \\
\hline $\mathbf{2 7 0}$ & 0 & 256 & 0 \\
\hline $\mathbf{3 1 5}$ & 0 & 0 & 256 \\
\hline $\mathbf{3 6 0}$ & 0 & 0 & 0 \\
\hline
\end{tabular}

If we want to show the pattern of increase and decrease in RGB values, the diagram in Figure 5 will be obtained. In this diagram, the three Red-Green-Blue value variations are shown in the upper part, and then the combination can be seen in the lower. 



Figure 5. Diagrams showing the individual variation of RGB values (upper) and the charts' combination (below) related to the proposed color circle.

Consequently, we can further divide the whole circle and obtained finer patterns. Indeed, by this act, we will make higher the resolution of the color pallet we use for vector data direction visualization purposes (Table 3).

Table 3. RGB values for the new color circle with 8,16 , and 32 sectors.

\begin{tabular}{|r|r|r|r|}
\hline & \multicolumn{1}{|c|}{ R } & \multicolumn{1}{|c|}{ G } & \multicolumn{1}{|c|}{ B } \\
\hline $\mathbf{0}$ & 0 & 0 & 0 \\
\hline $\mathbf{4 5}$ & 256 & 0 & 0 \\
\hline $\mathbf{9 0}$ & 0 & 256 & 0 \\
\hline $\mathbf{1 3 5}$ & 0 & 0 & 256 \\
\hline $\mathbf{1 8 0}$ & 0 & 0 & 0 \\
\hline $\mathbf{2 2 5}$ & 256 & 0 & 0 \\
\hline $\mathbf{2 7 0}$ & 0 & 256 & 0 \\
\hline 315 & 0 & 0 & 256 \\
\hline 360 & 0 & 0 & 0 \\
\hline
\end{tabular}

\begin{tabular}{|r|r|r|r|}
\hline & \multicolumn{1}{|c|}{$\mathbf{R}$} & \multicolumn{1}{|c|}{ G } & \multicolumn{1}{|c|}{ B } \\
\hline $\mathbf{0}$ & 0 & 0 & 0 \\
\hline $\mathbf{2 2 . 5}$ & 128 & 0 & 0 \\
\hline $\mathbf{4 5}$ & 256 & 0 & 0 \\
\hline $\mathbf{6 7 . 5}$ & 128 & 128 & 0 \\
\hline $\mathbf{9 0}$ & 0 & 256 & 0 \\
\hline $\mathbf{1 1 2 . 5}$ & 0 & 128 & 128 \\
\hline $\mathbf{1 3 5}$ & 0 & 0 & 256 \\
\hline $\mathbf{1 5 7 . 5}$ & 0 & 0 & 128 \\
\hline $\mathbf{1 8 0}$ & 0 & 0 & 0 \\
\hline $\mathbf{2 0 2 . 5}$ & 128 & 0 & 0 \\
\hline $\mathbf{2 2 5}$ & 256 & 0 & 0 \\
\hline $\mathbf{2 4 7 . 5}$ & 128 & 128 & 0 \\
\hline $\mathbf{2 7 0}$ & 0 & 256 & 0 \\
\hline $\mathbf{2 9 2 . 5}$ & 0 & 128 & 128 \\
\hline $\mathbf{3 1 5}$ & 0 & 0 & 256 \\
\hline $\mathbf{3 3 7 . 5}$ & 0 & 0 & 128 \\
\hline $\mathbf{3 6 0}$ & 0 & 0 & 0 \\
\hline
\end{tabular}

\begin{tabular}{|c|c|c|c|}
\hline & R & G & B \\
\hline 0 & 0 & 0 & 0 \\
\hline 11.25 & 64 & 0 & 0 \\
\hline 22.5 & 128 & 0 & 0 \\
\hline 33.75 & 192 & 0 & 0 \\
\hline 45 & 256 & 0 & 0 \\
\hline 56.25 & 192 & 64 & 0 \\
\hline 67.5 & 128 & 128 & 0 \\
\hline 78.75 & 64 & 192 & 0 \\
\hline 90 & 0 & 256 & 0 \\
\hline 101.25 & 0 & 192 & 64 \\
\hline 112.5 & 0 & 128 & 128 \\
\hline 123.75 & 0 & 64 & 192 \\
\hline 135 & 0 & 0 & 256 \\
\hline 146.25 & 0 & 0 & 192 \\
\hline 157.5 & 0 & 0 & 128 \\
\hline 168.75 & 0 & 0 & 64 \\
\hline 180 & 0 & 0 & 0 \\
\hline 191.25 & 64 & 0 & 0 \\
\hline 202.5 & 128 & 0 & 0 \\
\hline 213.75 & 192 & 0 & 0 \\
\hline 225 & 256 & 0 & 0 \\
\hline 236.25 & 192 & 64 & 0 \\
\hline 247.5 & 128 & 128 & 0 \\
\hline 258.75 & 64 & 192 & 0 \\
\hline 270 & 0 & 256 & 0 \\
\hline 281.25 & 0 & 192 & 64 \\
\hline 292.5 & 0 & 128 & 128 \\
\hline 303.75 & 0 & 64 & 192 \\
\hline 315 & 0 & 0 & 256 \\
\hline 326.25 & 0 & 0 & 192 \\
\hline 337.5 & 0 & 0 & 128 \\
\hline 348.75 & 0 & 0 & 64 \\
\hline 360 & 0 & 0 & 0 \\
\hline
\end{tabular}


The related RGB color patterns can be found in Fig. 6 for 8, 16, and 32 sectors for the proposed color circle.

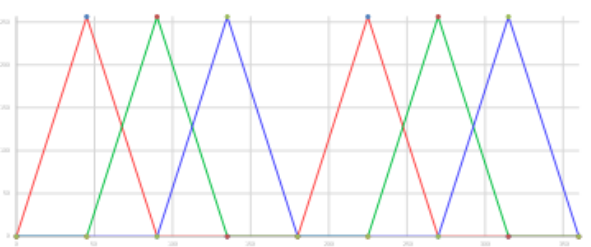

b
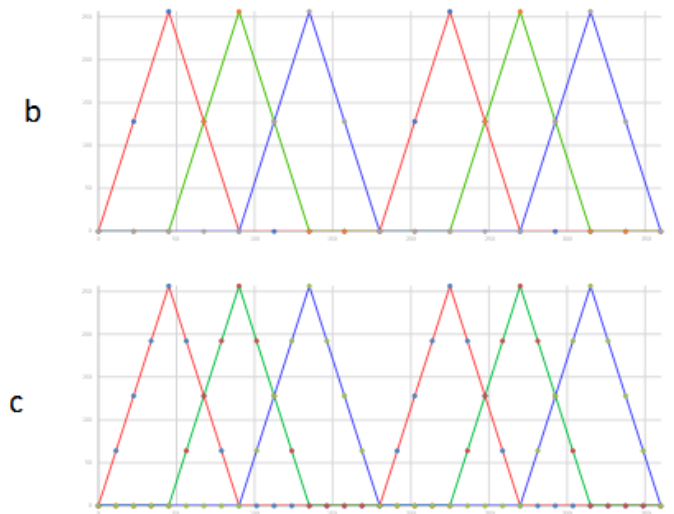

Figure 6. Diagrams showing the RGB combinations for the color circle with 8, 16 and 32 sectors (a, b, and c, respectively).

As can be seen in the above figure, the pattern remains constant for each color circle type. Only the number of the dots in the Edges is increased. In Figure7, the resulted color circles are shown:

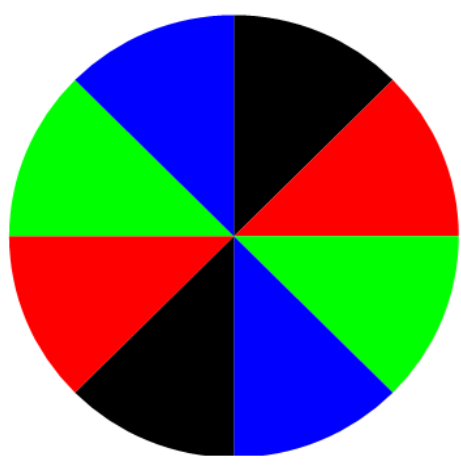

a

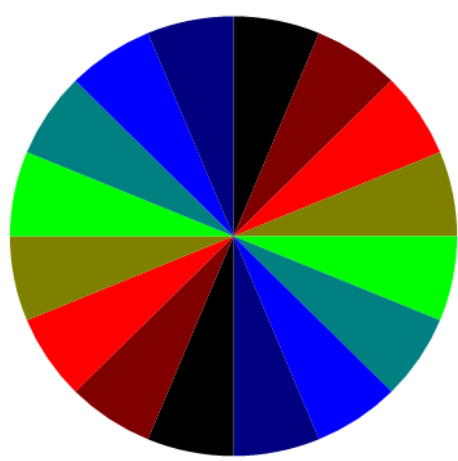

b

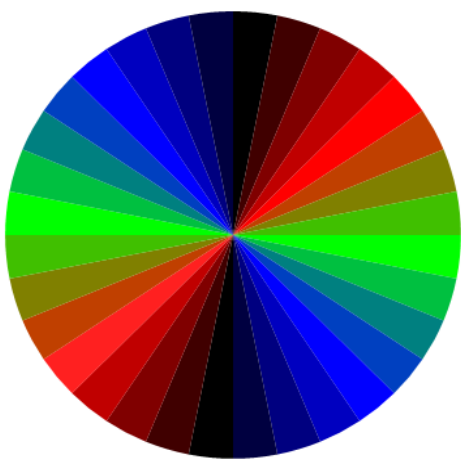

C

Figure 7. color circles with 8,16 and 32 sectors (a, b and c, respectively).

By continuing and further dividing the circle into more sectors, we can assign more colors to angle intervals by creating high-resolution color pallets to be used in mapping tools like GMT. Table 6 shows possible improvements in the color pallets or CPT files by dividing the circle into more sectors. Since the RGB values for use in mapping tools like GMT should be integer, the highest possible resolution in creating CPT files to be used in these environments is limited. For the proposed color circle, there can be a 2048 line at its highest. I will refer to the CPT files related to the proposed color circle as dir2048.CPT files. It should be noted that the circular color scale can visualize not only the direction of vector data but also the magnitude of the vectors can be shown by subdividing the sectors and changing the saturation of the colors in a way that it can represent the magnitude changes. We do not implement this method in the present study because our case study, which is the stress direction, does not contain magnitude data. 


\section{RESULTS AND DISCUSSION}

The color circle method is implemented for stress data available in the study area. The color pallet values are assigned to each cell, and interpolation is used. Figure 8 is obtained by applying the technique. In other words, for the stress or SHmax directions obtained by processing the single earthquake focal mechanism data, we use the proposed color circle. This figure contains some unseen anomalies in the stress directions and provides the first real color scaled stress map in the study area. There exist some anomalies in SHmax directions in several places that need careful examination to declare its relevance to the geology and tectonics of the study area, which is beyond the scope of this study. In Figure 8, the cyan bars show the Maximum Horizontal Stress directions from single focal mechanisms, with the small white circles showing the earthquake's location.

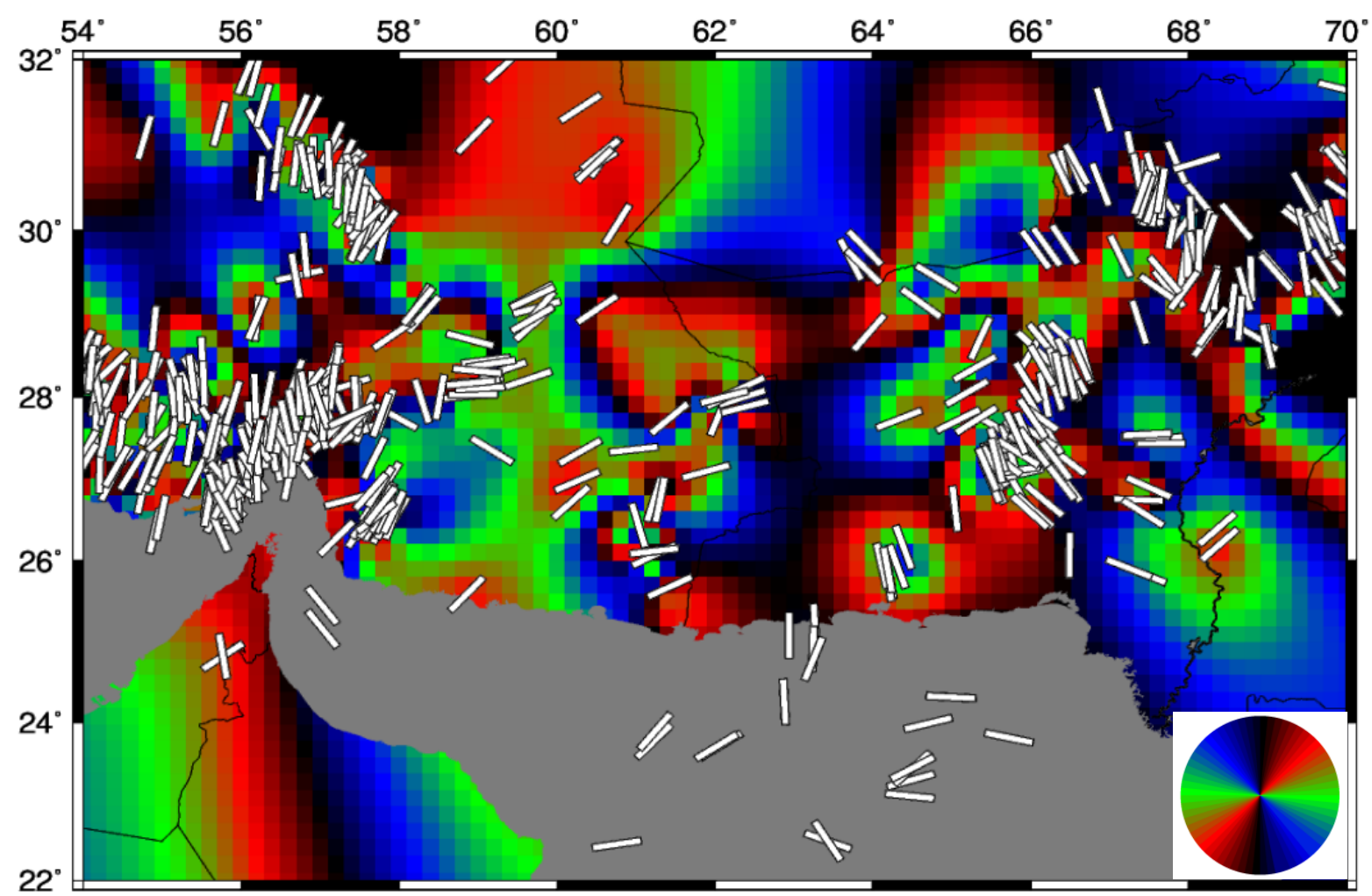

Figure 8. Stress direction mapping with the proposed circular color scale shown beside the map. White bars are the maximum stress direction from single earthquake focal mechanisms.

As shown in Figure 9, by adding the shear wave splitting studies already performed in the region, the stress database of the area can be improved. The shear wave splitting fast direction axes (Rahimzadeh et al., 2020) are added to the database to see their effect on the color scale introduced in this study (Figure 9). The red color corresponds to the NE-SW direction, which is the expected and justified direction of the maximum horizontal stress direction according to Iranian plateau convergence toward Eurasia. Thus adding auxiliary stress information to the single earthquake focal mechanisms can enhance the reliability and accuracy of the stress mapping process. In Figure 9, the cyan bars show the Maximum Horizontal Stress directions from single focal mechanisms. The yellow bars indicate the shear wave splitting fast direction axes (Rahimzadeh et al., 2020). 


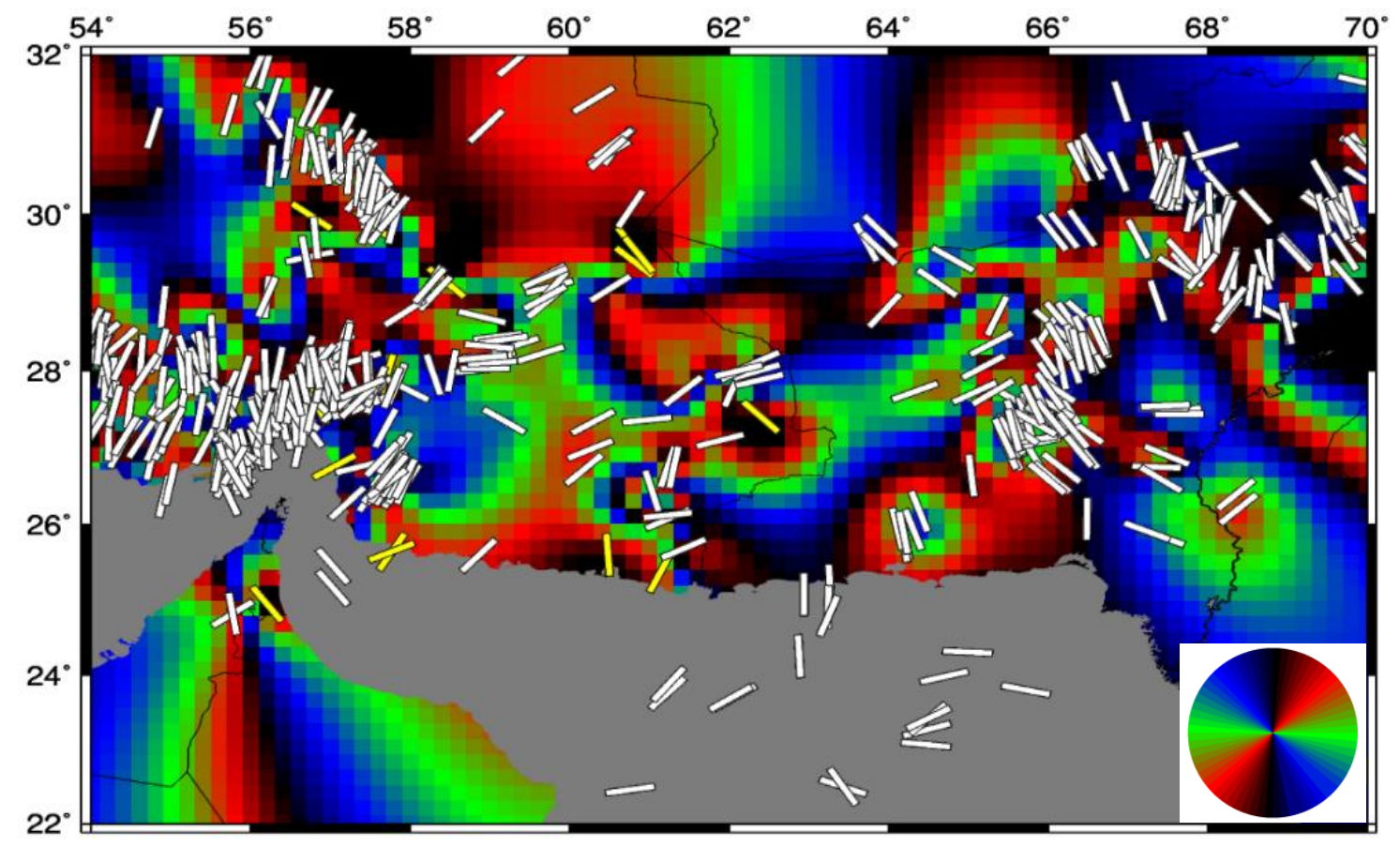

Figure 9. Stress direction mapping with the proposed circular color scale shown beside the map. The yellow bars indicate the shear wave splitting fast axes

It can be seen that the stress field map is changed as the result of adding the extra information from the shear wave splitting study performed in the region. Since the quality and accuracy of the map depending on the data used in its generation process, adding auxiliary information such as shear wave splitting and stress inversión results can improve the reliability of the obtained map. This is an example of implementing the newly proposed method and shows the importance and usefulness of data visualization techniques. The technique can be used in different science branches where vector data visualization can be of interest.

\section{CONCLUSIONS}

In the present study, a new color circle with central symmetry in colors is introduced and a new method in the visualization of vector data direction has been implemented. The compressional stress directions from single earthquake focal mechanisms are mapped as examples. The original and unseen anomalies in stress directions in the Makran region are observed for the first time in the study area. This study also showed that adding the anisotropy directions from previous studies in the region enhanced the correctness and reliability of the produces stress map.

\section{ABBREVIATIONS}

GCMT (HRVD): Global CMT Web Page. (n.d.). Retrieved from https://www.globalcmt.org/ IRSC: Iranian Seismological Center (n.d.). Retrieved from http://irsc.ut.ac.ir/bulletin.php ISC: International Seismological Centre. (n.d.). Retrieved from http://www.isc.ac.uk/ NEIC: New Earthquake Hazards Program. (n.d.). Retrieved from https://www.usgs.gov/naturalhazards/earthquake-hazards/national-earthquake-information-center-neic pp: Published papers cited in the manuscript.

ZUR_RMT: SED: Swiss Seismological Service. (n.d.). Retrieved from http://seismo.ethz.ch/en/home/ 


\section{REFERENCES}

Earthquake Hazards Program. National Earthquake Information Center (NEIC). (n.d.). https://www.usgs.gov/naturalhazards/earthquake-hazards/national-earthquake-information-center-neic.

Earthquake Hazards Program. National Earthquake Information Center (NEIC). (n.d.). https://www.usgs.gov/naturalhazards/earthquake-hazards/national-earthquake-information-center-neic.

Focal mechanism search. ISC. (n.d.). http://www.isc.ac.uk/iscbulletin/search/fmechanisms/.

Global CMT Catalog Search. Global Centroid Moment Tensor Catalog. (n.d.). https://www.globalcmt.org/CMTsearch.html.

Heidbach, O., Rajabi, M., Reiter, K., \& Ziegler, M. (2016). World Stress Map 2016. GFZ Data Services. In.

Heidbach, O., Rajabi, M., Reiter, K., \& Ziegler, M. (2016). World Stress Map 2016. GFZ Data Services. In.

International Seismological Centre. bulletin Search. (n.d.). http://irsc.ut.ac.ir/bulletin.php.

Masson, F., Chéry, J., Hatzfeld, D., Martinod, J., Vernant, P., Tavakoli, F., \& Ghafory-Ashtiani, M. (2005). Seismic versus aseismic deformation in Iran inferred from earthquakes and geodetic data. Geophysical Journal International, 160(1), 217-226.

Raeesi, M., Zarifi, Z., Nilfouroushan, F., Boroujeni, S. A., \& Tiampo, K. (2017). Quantitative analysis of seismicity in Iran. Pure and Applied Geophysics, 174(3), 793-833.

Rahimzadeh, S., Moradi, A., \& Kaviani, A. (2020). Investigating the strength and trend of seismic anisotropy in the western part of Makran subduction zone and southeast of Iran. Physics of the Earth and Planetary Interiors, 298, 106345. doi:10.1016/j.pepi.2019.106345. Search Earthquake Catalog. (n.d.). Retrieved from SED: Swiss Seismological Service. (n.d.). Retrieved from http://seismo.ethz.ch/en/home/

SED: Home. SED | Home. (n.d.). http://seismo.ethz.ch/en/home/.

Shevell, S. K. (2003). The science of color: Elsevier.

Vernant, P., Nilforoushan, F., Hatzfeld, D., Abbassi, M. R., Vigny, C., Masson, F., . . Bayer, R. (2004). Present-day crustal deformation and plate kinematics in the Middle East constrained by GPS measurements in Iran and northern Oman. Geophysical Journal International, 157(1), 381-398.

Zoback, M. L. (1992). First-and second-order patterns of stress in the lithosphere: The World Stress Map Project. Journal of Geophysical Research: Solid Earth, 97(B8), 11703-11728. 